\title{
Use of Preclinical Drug Vs. Food Choice Procedures to Evaluate Candidate Medications for Cocaine Addiction
}

Matthew L. Banks, PharmD, PhD ${ }^{1,2, *}$ Blake A. Hutsell, PhD ${ }^{1}$

Kathryn L. Schwienteck, BS ${ }^{1,3}$

S. Stevens Negus, $P h D^{1,2}$

\author{
Address \\ *,1Department of Pharmacology and Toxicology, Virginia Commonwealth \\ University, 410 North 12th Street, PO Box 980613, Richmond, VA 23298, USA \\ Email:mbanks7@vcu.edu \\ ${ }^{2}$ Institute for Drug and Alcohol Abuse Studies, Virginia Commonwealth University, \\ Richmond, VA, USA \\ ${ }^{3}$ School of Pharmacy, Virginia Commonwealth University, Richmond, VA, USA
}

Published online: 16 April 2015

(C) Springer International Publishing AG 2015

This article is part of the Topical Collection on Substance Use Disorders

Keywords Choice - Addiction - Nonhuman primate - Preclinical model · Medication

\section{Opinion statement}

Drug addiction is a disease that manifests as an inappropriate allocation of behavior towards the procurement and use of the abused substance and away from other behaviors that produce more adaptive reinforcers (e.g., exercise, work, family, and social relationships). The goal of treating drug addiction is not only to decrease drug-maintained behaviors but also to promote a reallocation of behavior towards alternative, nondrug reinforcers. Experimental procedures that offer concurrent access to both a drug reinforcer and an alternative, nondrug reinforcer provide a research tool for assessment of medication effects on drug choice and behavioral allocation. Choice procedures are currently the standard in human laboratory research on medications development. Preclinical choice procedures have been utilized in biomedical research since the early 1940s, and during the last 10-15 years, their use for evaluation of medications to treat drug addiction has increased. We propose here that parallel use of choice procedures in preclinical and clinical studies will facilitate translational research on development of medications to treat cocaine addiction. In support of this proposition, a review of the literature suggests 
strong concordance between preclinical effectiveness of candidate medications to modify cocaine choice in nonhuman primates and rodents and clinical effectiveness of these medications to modify either cocaine choice in human laboratory studies or metrics of cocaine abuse in patients with cocaine use disorder. The strongest evidence for medication effectiveness in preclinical choice studies has been obtained with maintenance on the monoamine releaser $d$-amphetamine, a candidate agonist medication for cocaine use analogous to use of methadone to treat opioid abuse or nicotine formulations to treat tobacco dependence.

\section{Introduction}

Drug addiction is a significant and global public health problem [1]. Although there are Food and Drug Administration (FDA)-approved pharmacotherapies for addiction to some drugs, such as heroin, nicotine, and ethanol, FDA-approved pharmacotherapies are absent for addiction to many other abused drugs, such as cocaine, methamphetamine, and marijuana. Moreover, the development of safer and more efficacious medications to treat addiction to all classes of abused drugs remains a priority for drug abuse research. Preclinical drug selfadministration procedures have been invaluable in identifying neurobiological and environmental mechanisms that contribute to abuse-related drug effects [2]. In addition, preclinical evaluation of effects produced by candidate medications on drug self-administration has demonstrated good, but not perfect, concordance with both medication effects in human laboratory drug selfadministration studies and metrics of drug abuse in clinical trials [3-5]. Two experimental features that appear to promote accurate translation of preclinical to clinical results are (1) repeated treatment with the candidate medication to match the subchronic-to-chronic treatment regimens commonly employed in clinical drug abuse treatment and (2) assessment of medication effects on choice between the target drug of abuse and an alternative nondrug reinforcer such as food (in laboratory animals) or money (in humans). Accordingly, this review has two goals. First, we provide a brief overview of drug self-administration procedures that provide concurrent access to a drug and an alternative, nondrug reinforcer, and we discuss the rationale for using these procedures in the medication development process. Second, we discuss the major findings of both pharmacological and non-pharmacological treatments on intravenous cocaine vs. food choice in preclinical studies. The objective is to assess the translational validity of candidate medication treatment results from preclinical cocaine vs. food choice studies to results from human laboratory studies and clinical trials.

\section{Core attributes of preclinical choice procedures}

In both preclinical and human laboratory drug self-administration procedures, the performance of some operant behavior (e.g., pressing a response key) produces the delivery of a unit drug dose (e.g., intravenous (IV) cocaine delivery via an indwelling IV catheter). If responding for any dose of a given drug occurs at higher rates than responding for vehicle, then the drug is considered to function as a reinforcer and to produce reinforcing effects [6]. A well-established concordance exists between drugs that function as reinforcers in drug self-administration procedures and drugs that are abused by humans [6]. Overall, there is a rich body of literature suggesting that preclinical drug self-administration procedures are good models of human drug abuse and addiction.

Drug self-administration procedures are also widely used to assess potential treatments for drug abuse and addiction [3, 7]. Although many variants of drug self-administration procedures exist, this review will focus on preclinical drug 
vs. food choice procedures $[8,9]$. In a drug vs. food choice procedure, behavior is maintained on two different response manipulanda by two different consequent stimuli. For example, responding on one manipulandum results in the IV delivery of a drug dose, and responding on a different, concurrently available manipulandum results in the delivery of a food pellet. Thus, these drug selfadministration procedures are often referred to as "choice" procedures because research subjects allocate behavior, or "choose," between the concurrently available consequent stimuli. Three main reasons support the use of preclinical choice procedures to evaluate candidate treatments for drug addiction. First, drug addiction is defined by maladaptive allocation of behavior and has been defined as a "disorder of choice" $[2,10]$. Specifically, drug addiction implies maladaptive behavioral allocation towards drug use at the expense of behaviors that produce more adaptive and socially acceptable reinforcers. Furthermore, the ultimate goal in treating drug addiction is not merely to decrease drugmaintained behavior but also to increase behavior maintained by nondrug reinforcers [11, 12]. Preclinical choice procedures allow for explicit assessment of behavioral allocation between concurrently available reinforcers during a pharmacological treatment. Second, human laboratory drug self-administration studies rely almost exclusively on drug vs. nondrug choice procedures to assess candidate medication efficacy $[4,5,13]$, and increased homology between preclinical and human laboratory experimental procedures can reasonably be expected to facilitate translation of results. Lastly, choice procedures generate dependent measures that facilitate interpretation of medication effects. Thus, a goal of any candidate medication is to decrease drug-taking behavior; however, a decrease in drug self-administration can be achieved either by a selective reduction in reinforcing effects of the abuse drug (a desirable outcome that preserves other behaviors) or by a nonselective decrease in a broad range of behaviors (an undesirable outcome suggestive of behavioral or physiological toxicity). Choice procedures generate distinct dependent measures for medication effects on drug reinforcement (measured by allocation of behavior) and general behavioral competence (measured by rate of behavior) (Fig. 1). In choice procedures, an ideal medication effect is a reduction in drug choice accompanied by a reciprocal increase in choice of the alternative, nondrug reinforcer. Conversely, undesirable medication effects would include (a) no change in behavior, (b) an increase in drug choice, or (c) a reduction in choice of both drug and the nondrug alternative without a change in the proportion of behavior allocated to drug.

\section{Evaluation of candidate medications in preclinical drug vs. food choice procedures}

Preclinical drug vs. food choice procedures were established first in nonhuman primates, and these procedures have been used for more than 30 years to evaluate candidate medications. The development of choice procedures in rodents has been a more recent development, but conduct of choice procedures in rodents is accelerating. A literature search of PubMed revealed a total of 21 published studies that have determined subchronic ( $\geq 3$ consecutive treatment days) pharmacological experimental treatment effects on cocaine vs. food choice in rats and nonhuman primates. This body of preclinical literature is summarized in Table 1. 

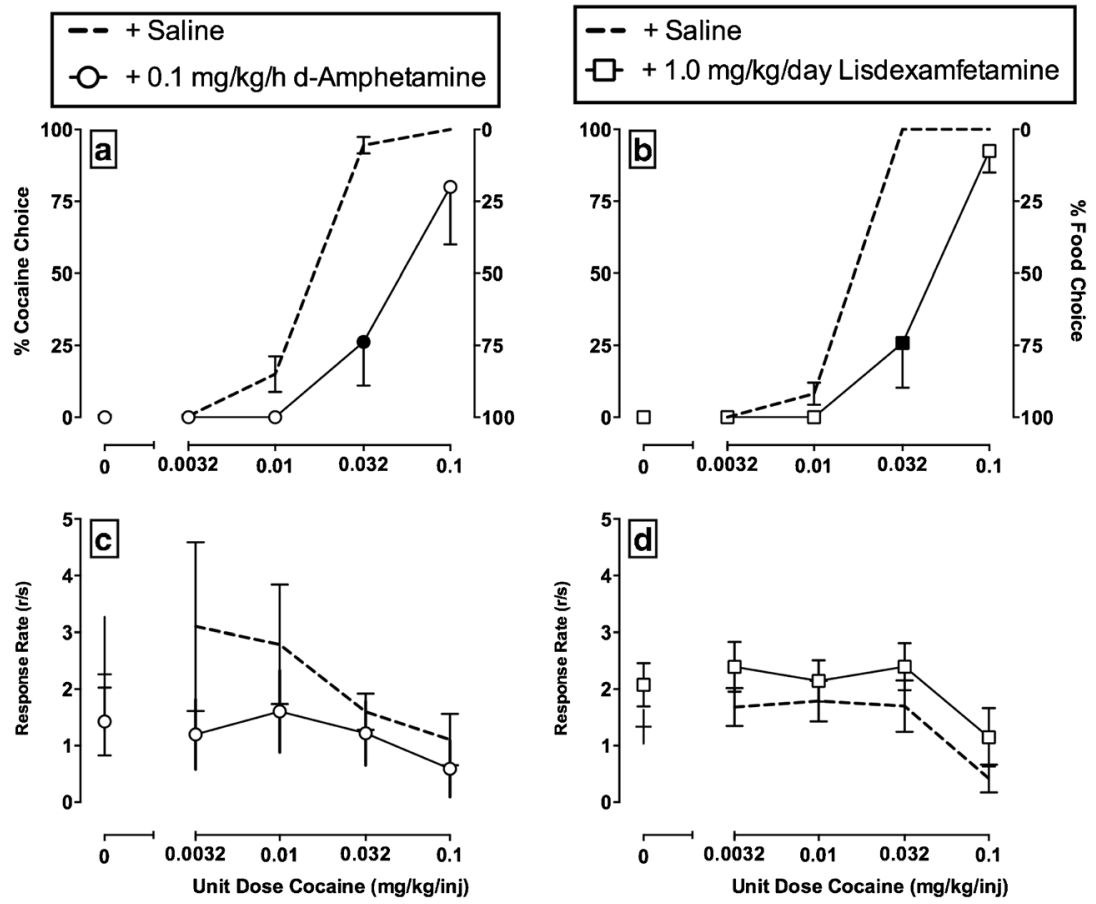

Fig. 1. Choice between different unit cocaine doses $(0-0.1 \mathrm{mg} / \mathrm{kg} /$ injection) and 1-g food pellets in rhesus monkeys under a concurrent FR10:FR100 schedule of cocaine injections and food availability. Amphetamine [21••] and lisdexamfetamine treatment [32••] results have been previously published. Abscissae: unit dose of cocaine in milligrams per kilogram per injection. Top left ordinate: percent cocaine choice. Top right ordinate: percent food choice. Bottom ordinate: Rates of operant responding in responses per second. All dashed lines represent the mean $( \pm S E M)$ of three consecutive days of saline treatment before pharmacological treatment initiation. Data points represent the mean of last three treatment days of each 7-day treatment period. Filled symbols indicate statistical significance $(p<0.05)$ compared to saline conditions. These results demonstrate three main findings from drug vs. food choice procedures. First, cocaine vs. food choice increases in a monotonic function as the unit cocaine dose increases. Second, rates of operant responding are not predictive of cocaine vs. food choice nor are rates of responding predictive of pharmacological treatment effects on cocaine vs. food choice. Finally, subchronic treatment with amphetamine or lisdexamfetamine decreased cocaine choice and produced a reciprocal increase in food choice.

Monoamine releasers, such as $d$-amphetamine, represent a class of drugs that function as substrates for dopamine (DA), norepinephrine (NE), and/or serotonin (5HT) transporters (DAT, NET, and SERT) and exert their pharmacological effects by promoting neurotransmitter release independent of neuronal activity [14]. Several monoamine releasers are currently FDA-approved and clinically used as pharmacotherapies for attention deficit hyperactivity disorder, obesity, and narcolepsy, and they may also have utility as "agonist-based" medications for cocaine addiction analogous to use of methadone maintenance for opioid abuse or nicotine formulations to treat tobacco dependence $[15,16]$. The prototype monoamine releaser amphetamine has been the most extensively studied monoamine releaser as a candidate medication to treat cocaine abuse. Amphetamine maintenance has demonstrated efficacy in most, but not 
Table 1. Summary of published manuscripts reporting subchronic ( $\geq 3$ consecutive days) candidate medication treatment effects on IV cocaine self-administration under a concurrent choice schedule

\begin{tabular}{|c|c|c|c|c|c|c|}
\hline$\#$ & $\begin{array}{l}\text { Cocaine Dose } \\
\text { (mg/kg/inj) }\end{array}$ & $\begin{array}{l}\text { Alternative } \\
\text { reinforcer }\end{array}$ & Species & $\begin{array}{l}\text { Main treatment } \\
\text { examined }\end{array}$ & $\begin{array}{l}\text { Effect on } \\
\text { cocaine choice }\end{array}$ & Ref \\
\hline & \multicolumn{6}{|c|}{ Monoamine releaser treatments } \\
\hline 1 & $0.0032-0.1$ & Food pellet & Rhesus monkey & $d$-Amphetamine & $\downarrow$ & [22] \\
\hline 2 & $0-1$ & Ensure liquid food & Rat & $d$-Amphetamine & $\downarrow$ & {$[23 \bullet]$} \\
\hline 3 & $0.0032-0.1$ & Food pellet & Rhesus & $\begin{array}{l}d \text {-Amphetamine, } \\
\text { phenmetrazine, and } \\
\text { phendimetrazine }\end{array}$ & $\downarrow$ & {$[21 \bullet \bullet]$} \\
\hline 4 & $0.0032-0.1$ & Food pellet & Rhesus & 5 monoamine releasers & $\downarrow$ & [27] \\
\hline 5 & $0.0032-0.1$ & Food pellet & Rhesus & Phenmetrazine & $\downarrow$ & [28] \\
\hline 6 & $0.0032-0.1$ & Food pellet & Rhesus & Phendimetrazine & $\downarrow$ & [31] \\
\hline 7 & $0.0032-0.1$ & Food pellet & Rhesus & Lisdexamfetamine & $\downarrow$ & {$[32 \bullet \bullet]$} \\
\hline \multirow[t]{2}{*}{8} & $0.0032-0.1$ & Food pellet & Rhesus & PAL-542 & - & [29] \\
\hline & \multicolumn{6}{|c|}{ Monoamine uptake inhibitor treatments } \\
\hline \multirow[t]{2}{*}{1} & $0.0032-0.1$ & Food pellet & Rhesus & Cocaine & - & [22] \\
\hline & \multicolumn{6}{|c|}{ Dopamine receptor antagonist, partial agonist, and agonist treatments } \\
\hline 9 & $0.05-0.3$ & Food pellet & Rhesus & $\begin{array}{l}\text { Haloperidol and } \\
\text { chlorpromazine }\end{array}$ & $\uparrow$ & [58] \\
\hline 1 & $0.0032-0.1$ & Food pellet & Rhesus & Flupenthixol & $\uparrow$ & [22] \\
\hline 10 & $0.003-0.3$ & Food pellet & Rhesus & Quetiapine & - & [59] \\
\hline 11 & $0.01-1.0$ & Food pellet & Rhesus & $\begin{array}{c}\text { Buspirone and } \\
\text { PG01037 }\end{array}$ & - & [62] \\
\hline 12 & $0.003-0.1$ & $\begin{array}{l}10 \% \text { Condensed } \\
\text { milk }\end{array}$ & Squirrel monkey & Aripiprazole & - & [68] \\
\hline 13 & $0-1$ & Ensure liquid food & Rat & Aripiprazole & - & [67] \\
\hline 14 & $0.003-0.1$ & Food pellet & $\begin{array}{c}\text { Cynomolgus } \\
\text { monkey }\end{array}$ & Aripiprazole & $-/ \downarrow$ & [69] \\
\hline 15 & $0.01-1.0$ & Food pellet & Rhesus & PG619 & - & [77] \\
\hline \multirow[t]{2}{*}{14} & $0.003-0.1$ & Food pellet & Cynomolgus & $(-)-N P A$ & $-/ \downarrow$ & [69] \\
\hline & \multicolumn{6}{|c|}{ Opioid agonist and antagonist treatments } \\
\hline 16 & $0.0032-0.1$ & Food pellet & Rhesus & Methadone & - & [77] \\
\hline 17 & $0.0032-0.1$ & Food pellet & Rhesus & U50,488 & $\uparrow$ & [73] \\
\hline 17 & $0.0032-0.1$ & Food pellet & Rhesus & nor-BNI & - & [73] \\
\hline \multirow[t]{2}{*}{18} & $0.0032-0.1$ & Food pellet & Rhesus & nor-BNI & - & [74] \\
\hline & Other treatments & & & & & \\
\hline 19 & $0.1-0.3$ & Food pellet & Rhesus & Lithium & - & [79] \\
\hline 20 & 0.25 & Saccharin & Rat & Diazepam & $\downarrow$ & {$[81 \bullet \bullet]$} \\
\hline 21 & $0-1$ & Ensure liquid food & Rat & Xanomeline & $\downarrow$ & {$[82 \bullet \bullet]$} \\
\hline
\end{tabular}

Columns show cocaine dose(s), the alternative reinforcer(s), the species in which studies were conducted, the primary treatment examined and outcome, and the reference. Studies are categorized as treatment compound classes as discussed in the manuscript. A downward arrow ( $\downarrow$ ) represents a pharmacological treatment that decreased cocaine choice. An upward arrow $(\uparrow)$ represents a pharmacological treatment that increased cocaine choice. A horizontal dash line (-) represents a pharmacological treatment that did not significantly alter cocaine choice up to doses that produced other behavioral effects, such as suppression of rates of operant behavior 
all, double-blind, placebo-controlled clinical trials [17-20]. Consistent with results from these clinical trials, preclinical choice studies in both nonhuman primates $[21 \bullet \bullet, 22]$ (Fig. 1) and rats [23•] and human laboratory choice studies $[24,25]$ have also reported that subchronic $d$ amphetamine treatment decreases cocaine choice. Altogether, amphetamine treatment has consistently displayed efficacy to decrease cocaine choice across a broad range of experimental conditions and species.

The efficacy of monoamine releaser treatments to decrease cocaine choice has been extended to other monoamine releasers, such as methamphetamine, and other monoamine releaser formulations, such as prodrugs, that are metabolized to an active monoamine releaser metabolite. For example, methamphetamine treatment decreased cocaine use in a double-blind, placebocontrolled clinical trial [26]. Consistent with this clinical trial, subchronic treatment with methamphetamine attenuated cocaine vs. food choice in rhesus monkeys [27]. In addition to methamphetamine, the monoamine releaser phenmetrazine has also demonstrated efficacy to decrease cocaine vs. food choice in nonhuman primates $[21 \bullet \bullet, 27,28]$. However, selectivity for releasing dopamine (DA) vs. serotonin (5HT) appears to be an important determinant of monoamine releaser treatment effects on cocaine vs. food choice, such that higher selectivity for releasing DA compared to 5HT was associated with greater reductions in cocaine choice $[27,29]$. Regarding prodrugs, there are currently two clinically available compounds that produce pharmacological effects using this mechanism: phendimetrazine and lisdexamfetamine. Phendimetrazine is a schedule III controlled substance and is the $\mathrm{N}$-methyl analog of phenmetrazine, and it functions as a prodrug for the monoamine releaser phenmetrazine [30]. Consistent with preclinical results described above with phenmetrazine treatment, phendimetrazine treatment also decreased cocaine vs. food choice in nonhuman primates $[21 \bullet \bullet, 31]$. Similarly consistent with the amphetamine treatment results described earlier, the amphetamine prodrug lisdexamfetamine also decreased cocaine vs. food choice in nonhuman primates [32••] (Fig. 1). Overall, these preclinical data extend the spectrum of monoamine releasers that possess therapeutic efficacy and that have potential to serve as candidate medications for the treatment of cocaine addiction.

Another "agonist-based" pharmacotherapy approach for cocaine addiction might be other monoamine uptake inhibitors because these compounds would share the same mechanism of action as cocaine. To date, treatments with four different monoamine uptake inhibitors on cocaine-maintained behaviors have been examined in both human laboratory studies and clinical trials: mazindol, methylphenidate, bupropion, and modafanil. Both mazindol $[33,34]$ and bupropion $[35,36]$ failed to significantly decrease cocaine use in clinical trials. Methylphenidate attenuated cocaine vs. money choice in a one human laboratory study [37], but it did not significantly alter cocaine use in clinical trials [38-41]. Modafanil decreased cocaine vs. money choice in one human laboratory study [42] and cocaine use in one clinical trial [43]; however, a more recent human laboratory study [44] and four other clinical trials [20, 38, 45, 46] reported no significant effect of modafanil on cocaine use. In contrast to this 
extensive literature on effects of monoamine transporter inhibitors in humans, to date, none of the compounds referenced above have been examined as treatments in preclinical cocaine vs. food choice procedures. However, consistent with the generally poor effectiveness of other monoamine transporter inhibitors to decrease cocaine use in humans, subchronic treatment with cocaine itself did not significantly attenuate cocaine vs. food choice in rhesus monkeys [22].

\section{Dopamine antagonists and partial agonists}

Some classes of abused drugs act at receptors for which antagonists are avail-

able, and in these cases, antagonists have been evaluated for their effectiveness to reduce drug-taking behavior. For example, opioid agonists like heroin produce their effects by binding to and activating mu opioid receptors, and the mu opioid antagonist naltrexone is an FDA-approved pharmacotherapy for the treatment of opioid abuse, although patient compliance remains a significant obstacle for sustained naltrexone treatment efficacy [47]. Consistent with the therapeutic efficacy of mu opioid antagonists in detoxified heroin-dependent humans [48], chronic treatment with naltrexone or another mu opioid antagonist, naloxone, decreased heroin choice and increased food choice in nonopioid-dependent nonhuman primates [49]. Cocaine produces its abuserelated effects primarily by binding DA transporters and inhibiting DA uptake, and drugs that block cocaine binding without also blocking DA uptake have not been identified. However, cocaine effects on DA transporters indirectly increase synaptic DA levels and subsequent activation of DA receptors, and as a result, DA receptor antagonists have been evaluated as candidate pharmacotherapies for treating cocaine addiction.

In clinical trials, DA D2 receptor antagonist-based pharmacotherapy with either risperidone [18, 50-53] or olanzapine [54-56] failed to demonstrate therapeutic efficacy for cocaine addiction, and this approach is generally associated with poor patient compliance [57•]. In agreement with these clinical results, subchronic treatment with the DA D2 antagonists flupenthixol, haloperidol, chlorpromazine, and quetiapine did not decrease and sometimes increased cocaine choice in nonhuman primate preclinical studies $[22,58,59]$. Consistent with these published results, subchronic treatment with DA antagonist risperidone also failed to attenuate cocaine vs. food choice in rhesus monkeys (Hutsell, Negus, and Banks, unpublished observations).

Targeting other DA receptor subtypes, such as D1 or D3 receptors, has not improved therapeutic efficacy of DA antagonists to reduce cocaine use in choice studies. For this approach, buspirone has received the most recent attention. Buspirone is a partial agonist at serotonin 1A receptors that also functions as a DA receptor antagonist with selectivity for D3 and D4 receptors compared to D2 receptors [60]. Buspirone did not significantly attenuate cocaine use in either a clinical trial [61] or in nonhuman primates choosing between cocaine injections and food pellets [29]. Moreover, subchronic treatment with another selective DA D3 antagonist (PG01037) also did not attenuate cocaine vs. food choice in nonhuman primates [62]. Finally, D1 antagonists have not yet been tested in preclinical studies of cocaine vs. food choice, but subchronic treatment with the D1 antagonist ecopipam (SCH39166) increased cocaine choice in humans [63]. Overall, this body of literature does not support utility of DA antagonists as pharmacotherapies for cocaine abuse. 
DA receptor partial agonists have also been examined as candidate pharmacotherapies with the idea that they might attenuate cocaine effects while producing fewer undesirable effects than DA receptor antagonists; however, these partial agonists have also failed to produce favorable effects. Both human laboratory studies [64, 65] and clinical trials [66] reported no significant effect on cocaine use during treatment with the DA D2 partial agonist aripiprazole. Consistent with these human results, subchronic aripiprazole treatment also failed to attenuate cocaine vs. food choice in both rats [67] and nonhuman primates [68, 69]. Similarly, subchronic treatment with a DA D3-selective partial agonist (PG619) also failed to attenuate cocaine vs. food choice in nonhuman primates [70].

The dynorphin/ kappa opioid receptor (KOR) system has also been implicated as another potential therapeutic target in the treatment of cocaine addiction [71]. To date, no double-blind placebo-controlled clinical trials have been conducted with either kappa opioid agonist or kappa opioid antagonist treatments in cocaine-addicted individuals. In a human laboratory study, pretreatment with the kappa agonist enadoline did not alter cocaine vs. money choice [72]. Negus [73] reported that subchronic treatment with the kappa-opioid agonist U50,488 produced a dose-dependent increase in cocaine vs. food choice, and this U50,488 effect was blocked by the kappa antagonist norbinaltorphimine (nor-BNI). Nor-BNI treatment alone has failed to alter cocaine vs. food choice under multiple experimental conditions [73, 74]. However, until data are available from either human laboratory or clinical trials, the predictive validity of kappa antagonist treatments in preclinical models of cocaine addiction remains unknown.

Other opioid receptor mechanisms have also been examined. Subchronic treatment with the mu opioid partial agonist buprenorphine decreased cocaine vs. money choice in humans $[75,76]$ whereas treatment with the mu opioid full agonist methadone was ineffective [76]. Consistent with this human laboratory study, subchronic treatment with the mu opioid agonist methadone did not significantly decrease cocaine vs. food choice in nonhuman primates [77]. Recently, a clinical trial has been initiated determining the efficacy of buprenorphine treatment for cocaine addiction [78]. Overall, this body of literature suggests more research is warranted to ascertain the efficacy of buprenorphine as a pharmacotherapy for cocaine addiction.

Other pharmacological treatments

Three other classes of pharmacological compounds have been examined using subchronic treatment regimens in preclinical cocaine vs. food choice procedures. First, treatment with the mood-stabilizing compound lithium did not attenuate cocaine choice in nonhuman primates [79]. These lithium treatment effects in nonhuman primates are consistent with clinical studies examining lithium treatment in humans [80]. Second, treatment with the GABA-A receptor positive allosteric modulator diazepam attenuated cocaine vs. saccharin choice in rats $[81 \bullet \bullet]$. Lastly, treatment with the muscarinic receptor M1/M4

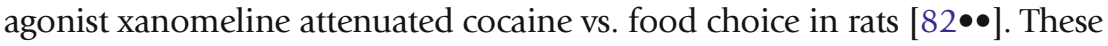


later two studies represent the first predinical studies to demonstrate a reduction in cocaine choice during subchronic treatment with a non-dopaminergic compound.

Non-pharmacological treatment strategies

In addition to these pharmacological treatment approaches, two general categories of non-pharmacological approaches have also been evaluated. The aim of these non-pharmacological approaches is to model aspects of broader social programs such as aftercare programs or punishment associated with law enforcement, as well as more targeted contingency management approaches that reinforce drug abstinence or punish drug use. The goal of all these nonpharmacological approaches is to manipulate choice contingencies and reallocate behavior away from drug choice and towards more socially appropriate reinforcers.

First, the simple introduction of an alternative, nondrug reinforcer decreases cocaine self-administration in rats [83], nonhuman primates [22, 84], and humans $[85,86 \bullet]$. Increasing the magnitude of the concurrently available alternative reinforcer also attenuates cocaine choice [22, 23•, 84, 85]. Furthermore, both preclinical and human laboratory studies have demonstrated that cocaine choice is sensitive to manipulations in the relative "cost" of cocaine or the alternative reinforcer. For example, increases in the cost for cocaine injections or decreases in the cost for the alternative reinforcer attenuates cocaine choice in rodents $[23 \bullet]$, nonhuman primates $[22,28,87]$, and humans [85, $86 \bullet$. Conversely, increases in cocaine choice can be produced by either increases in the cost for the alternative reinforcer or decreases in the cost for cocaine injections in rodents [23•], nonhuman primates [22, 28, 87], and humans $[85,86 \bullet]$. Moreover, a recent human laboratory study reported cocaine use patterns to be sensitive to income and cost variables [88•]. Overall, this body of literature supports treatment strategies that attempt to increase availability and reduce cost of nondrug alternative reinforcers while simultaneously raising the cost of drugs. An example of this type of non-pharmacological approach would be clinical contingency management programs [89].

A second non-pharmacological variable that has been examined in preclinical drug choice studies is the utility of punishment to decrease drug choice. Punishment, e.g., arrest by a police officer, is used within society as a potential method for decreasing drug-taking behavior. The most recent data from the National Survey on Drug Use and Health estimates 24.6 million persons in the USA aged 12 or older were current illicit drug users [90]. Insofar as drug abuse necessarily involves repeated episodes of drug use, a conservative estimate of 50 drug use episodes per year per user would imply more than one billion drug use episodes per year across all users. As an index of the frequency with which these drug use episodes resulted in arrest, the Federal Bureau of Investigation reported that approximately 1.5 million persons were arrested on drug abuse violation charges in 2013. This represented $13.3 \%$ of all arrests in the USA for that year [91], but these data suggest that roughly only $0.1 \%$ of illicit drug use episodes resulted in punishment in the form of arrest by a police officer. Preclinical data from drug vs. food choice studies suggest that this low probability of punishment likely limits its effectiveness. In nonhuman primates, for example, pairing a punisher (intravenous histamine 
injection) with cocaine injections reduced cocaine choice and promoted reallocation of behavior to food choice, and the effect of the punisher increased with its intensity; however, reducing the probability of punishment from $100 \%$ (punisher paired with every cocaine injection) to $33 \%$ (punishment paired with every third injection) completely eliminated the effect of punishment [92]. Moreover, the effectiveness of punishment also decreases hyperbolically with the delay to its delivery, such that the longer the delay between delivery of cocaine and delivery of the punisher, the less effective the punisher is to decrease subsequent cocaine choice [93]. It should also be noted that preclinical studies have demonstrated that punishment of choice maintained by nondrug alternative reinforcers can increase cocaine choice [92]. An understudied implication of this phenomenon is that high rates of drug use clinically may sometimes involve undesirable and/or unintentional punishment of alternative behaviors, and under these conditions, cocaine use can be expected to decline if punishment of alternative behaviors is reduced or eliminated.

\section{Implications and future directions}

Preclinical drug vs. food choice procedures offer an increasingly prominent methodology for evaluating candidate medications for treatment of addiction to cocaine and other drugs. These procedures model the human clinical context of cocaine use in a complex economy with multiple concurrently available reinforcers, are homologous to choice procedures used to assess candidate medications in clinical laboratory studies, and generate a rate-independent measure of cocaine's reinforcing efficacy. In studies conducted to date, cocaine choice is most reliably decreased by chronic treatment with monoamine releasers such as amphetamine. Novel compounds, such as the muscarinic agonist xanomeline, have also demonstrated treatment efficacy to decrease cocaine vs. food choice in preclinical studies. Drug choice can also be reduced by non-pharmacological manipulations that include (1) environmental enrichment that increases availability of alternative reinforcers, (2) increasing the relative cost of cocaine and/or decreasing the relative cost of alternative reinforcers, and (3) increasing the reliability of punishment for cocaine use and/or decreasing punishment of alternative behaviors. However, each of these treatment strategies is associated with obstacles. Pharmacotherapies produce side effects. For example, cardiovascular concerns of monoamine releaser treatment may hinder broad clinical deployment, but see Negus and Henningfield [16] for a commentary on potential side effects associated with monoamine releasers as candidate medications for cocaine addiction. Non-pharmacological treatments may be difficult to reliably institute. Conversely, cocaine vs. food choice is not reliably reduced, or is increased, by treatment with monoamine uptake inhibitors, DA receptor antagonists and DA receptor partial agonists, mu opioid receptor agonists, kappa opioid receptor agonists and antagonists, and other treatments including lithium.

One potential future direction will be to examine the role of certain biological variables, such as gender or genotype, as determinants of 
both drug vs. food choice and the sensitivity to pharmacological and non-pharmacological treatment manipulations. For example, gender differences have been reported in preclinical cocaine vs. food choice procedures $[94 \bullet, 95]$. These preclinical results are consistent with potential gender differences in human laboratory cocaine vs. money choice studies [96]. The degree to which these gender differences may impact sensitivity to candidate medications or non-pharmacological treatment strategies remains unexplored.

A second potential future direction to determine the predictive validity of preclinical drug vs. food choice procedures would be the determination of candidate medication effects for treatment of abuse to other drugs. For example, a recent preclinical study demonstrated no effect of bupropion treatment on methamphetamine vs. food choice in nonhuman primates [97]. Moreover, these preclinical results are consistent with both human laboratory [98] and double-blind placebo-controlled clinical trial recent demonstrating that bupropion did not decrease methamphetamine use [99]. The degree to which preclinical drug vs. food choice procedures are predictive of candidate medication effects for abused drugs other than cocaine remains to be fully ascertained. However, one roadblock in assessing the predictive validity of preclinical drug vs. food choice procedures is the availability of pharmacological compounds that have demonstrated therapeutic efficacy for decreasing drug use in humans. To date, no such compounds have been identified for methamphetamine addiction.

\section{Compliance with Ethics Guidelines}

\section{Conflict of Interest}

Matthew L. Banks and S. Stevens Negus both disclose grants funded by the National Institutes of Health. Blake A. Hutsell declares that he has no conflict of interest.

Kathryn L. Schwienteck declares that she has no conflict of interest.

\section{Human and Animal Rights and Informed Consent}

This article does not contain any studies with human or animal subjects performed by any of the authors.

\section{References}

Papers of particular interest, published recently, have been

highlighted as:

- Of importance

• Of major importance

1. UNODC. World Drug Report. 2012 (United Nations publication, Sales No. E.12.XI.1).

2. Kalivas PW, Volkow ND. The neural basis of addiction: a pathology of motivation and choice. Am J Psychiatry. 2005;162:1403-13.
3. Mello NK, Negus SS. Preclinical evaluation of pharmacotherapies for treatment of cocaine and opioid abuse using drug self-administration procedures. Neuropsychopharmacology. $1996 ; 14: 375-424$. 
4. Haney M, Spealman R. Controversies in translational research: drug self-administration.

Psychopharmacology. 2008;199:403-19.

5. Comer SD, Ashworth JB, Foltin RW, Johanson CE, Zacny JP, Walsh SL. The role of human drug selfadministration procedures in the development of medications. Drug Alcohol Depend. 2008;96:1-15.

6. Schuster CR. Drugs as reinforcers in monkey and man. Pharmacol Rev. 1975;27:511-21.

7. Howell LL, Negus SS. Monoamine transporter inhibitors and substrates as treatments for stimulant abuse. Adv Pharmacol. 2014;69:129-76.

8. Banks ML, Negus SS. Preclinical determinants of drug choice under concurrent schedules of drug self-administration. Adv Pharmacol Sci. 2012;2012:281768.

9. Negus SS, Banks ML. Medications development for opioid abuse. In: Pierce RC, Kenny PJ, editors. Addiction. New York: Cold Springs Harbor; 2013.

10. Heyman GH. Addiction: a disorder of choice. Cambridge: Harvard University Press; 2009.

11. Vocci FJ. Can replacement therapy work in the treatment of cocaine dependence? And what are we replacing anyway? Addiction. 2007;102:1888-9.

12. Volkow ND, Fowler JS, Wang G-J. The addicted human brain viewed in the light of imaging studies: brain circuits and treatment strategies. Neuropharmacology. 2004;47(Supplement 1):3-13.

13. Stoops WW, Rush CR. Agonist replacement for stimulant dependence: a review of clinical research. Curr Pharm Des. 2013;19:7026-35.

14. Rothman RB, Baumann MH, Dersch CM, Romero DV, Rice KC, Carroll FI, et al. Amphetamine-type central nervous system stimulants release norepinephrine more potently than they release dopamine and serotonin. Synapse. 2001;39:32-41.

15. Grabowski J, Shearer J, Merrill J, Negus SS. Agonist-like, replacement pharmacotherapy for stimulant abuse and dependence. Addict Behav. 2004;29:1439-64.

16. Negus SS, Henningfield J. Agonist medications for the treatment of cocaine use disorder.

Neuropsychopharmacology. 2014. doi:10.1038/npp. 2014.322.

17. Grabowski J, Rhoades H, Schmitz J, Stotts A, Daruzska LA, Creson D, et al. Dextroamphetamine for cocaine-dependence treatment: a double-blind randomized clinical trial. J Clin Psychopharmacol. 2001;21:522-6.

18. Grabowski J, Rhoades H, Stotts A, Cowan K, Kopecky C, Dougherty A, et al. Agonist-like or antagonist-like treatment for cocaine dependence with methadone for heroin dependence: two double-blind randomized clinical trials. Neuropsychopharmacology. 2004;29:969-81.

19. Mariani JJ, Pavlicova M, Bisaga A, Nunes EV, Brooks DJ, Levin FR. Extended-release mixed amphetamine salts and topiramate for cocaine dependence: a randomized controlled trial. Biol Psychiatry. 2012;72:950-6.

20. Schmitz JM, Rathnayaka N, Green C, Moeller FG, Dougherty AE, Grabowski J. Combination of modafinil and d-amphetamine for the treatment of cocaine dependence: a preliminary investigation. Front Psychiatry. 2012;3:77.

21.• Banks ML, Blough BE, Negus SS. Effects of 14-day treatment with the schedule III anorectic phendimetrazine on choice between cocaine and food in rhesus monkeys. Drug Alcohol Depend. 2013;131:204-13.

First demonstration of a prodrug (phendimetrazine) treatment efficacy on cocaine vs. food choice in monkeys.

22. Negus SS. Rapid assessment of choice between cocaine and food in rhesus monkeys: effects of environmental manipulations and treatment with d-amphetamine and flupenthixol. Neuropsychopharmacology. 2003;28:919-31.

23. Thomsen M, Barrett AC, Negus SS, Caine SB. Cocaine versus food choice procedure in rats: environmental manipulations and effects of amphetamine. J Exp Anal Behav. 2013;99:211-33.

First cocaine vs. food choice study in rodents to demonstrate amphetamine treatment efficacy.

24. Greenwald MK, Lundahl LH, Steinmiller CL. Sustained release d-amphetamine reduces cocaine but not "speedball"-seeking in buprenorphine-maintained volunteers: a test of dual-agonist pharmacotherapy for cocaine/heroin polydrug abusers.

Neuropsychopharmacology. 2010;35:2624-37.

25. Rush CR, Stoops WW, Sevak RJ, Hays LR. Cocaine choice in humans during D-amphetamine maintenance. J Clin Psychopharmacol. 2010;30:152-9.

26. Mooney ME, Herin DV, Schmitz JM, Moukaddam N, Green CE, Grabowski J. Effects of oral methamphetamine on cocaine use: a randomized, double-blind, placebo-controlled trial. Drug Alcohol Depend. 2009;101:34-41.

27. Banks ML, Blough BE, Negus SS. Effects of monoamine releasers with varying selectivity for releasing dopamine/norepinephrine versus serotonin on choice between cocaine and food in rhesus monkeys. Behav Pharmacol. 2011;22:824-36.

28. Banks ML, Blough BE, Stevens Negus S. Interaction between behavioral and pharmacological treatment strategies to decrease cocaine choice in rhesus monkeys. Neuropsychopharmacology. 2013;38:395-404.

29. Banks ML, Bauer CT, Blough BE, Rothman RB, Partilla JS, Baumann $\mathrm{MH}$, et al. Abuse-related effects of dual dopamine/serotonin releasers with varying potency to release norepinephrine in male rats and rhesus monkeys. Exp Clin Psychopharmacol. 2014;22:274-84.

30. Banks ML, Blough BE, Fennell TR, Snyder RW, Negus SS. Role of phenmetrazine as an active metabolite of phendimetrazine: evidence from studies of drug discrimination and pharmacokinetics in rhesus monkeys. Drug Alcohol Depend. 2013;130:158-66.

31. Banks ML, Blough BE, Fennell TR, Snyder RW, Negus SS. Effects of phendimetrazine treatment on cocaine vs food choice and extended-access cocaine consumption in rhesus monkeys. Neuropsychopharmacology. 2013;38:2698-707. 
32.• Banks ML, Hutsell BA, Blough BE, Poklis JL, Negus SS. Preclinical assessment of Lisdexamfetamine as an agonist medication candidate for cocaine addiction: effects in rhesus monkeys trained to discriminate cocaine or to self-administer cocaine in a cocaine versus food choice procedure. Int J Neuropsychopharmacol. 2015. doi:10. 1093/ijnp/pyv009.

First demonstration that the amphetamine prodrug

lisdexamfetamine produces amphetamine-like treatment efficacy on cocaine vs. food choice in monkeys.

33. Margolin A, Avants SK, Kosten TR. Mazindol for relapse prevention to cocaine abuse in methadone-maintained patients. Am J Drug Alcohol Abuse. 1995;21:469-81.

34. Stine SM, Krystal JH, Kosten TR, Charney DS. Mazindol treatment for cocaine dependence. Drug Alcohol Depend. 1995;39:245-52.

35. Margolin A, Kosten TR, Avants SK, Wilkins J, Ling W, Beckson $\mathrm{M}$, et al. A multicenter trial of bupropion for cocaine dependence in methadone-maintained patients. Drug Alcohol Depend. 1995;40:125-31.

36. Shoptaw $\mathrm{S}$, Heinzerling KG, Rotheram-Fuller E, Kao UH, Wang P-C, Bholat MA, et al. Bupropion hydrochloride versus placebo, in combination with cognitive behavioral therapy, for the treatment of cocaine abuse/ dependence. J Addict Dis. 2008;27:13-23.

37. Collins SL, Levin FR, Foltin RW, Kleber HD, Evans SM. Response to cocaine, alone and in combination with methylphenidate, in cocaine abusers with ADHD. Drug Alcohol Depend. 2006;82:158-67.

38. Grabowski J, Roache JD, Schmitz JM, Rhoades H, Creson D, Korszun A. Replacement medication for cocaine dependence: methylphenidate. J Clin Psychopharmacol. 1997;17:485-8.

39. Schubiner H, Downey KK, Arfken CL, Johanson C-E, Schuster CR, Lockhart N, et al. Double-blind placebocontrolled trial of methylphenidate in the treatment of adult ADHD patients with comorbid cocaine dependence. Exp Clin Psychopharmacol. 2002;10:286-94.

40. Levin FR, Evans SM, Brooks DJ, Garawi F. Treatment of cocaine dependent treatment seekers with adult ADHD: double-blind comparison of methylphenidate and placebo. Drug Alcohol Depend. 2007;87:20-9.

41. Dursteler-MacFarland KM, Farronato NS, Strasser J, Boss J, Kuntze MF, Petitjean SA, et al. A randomized, controlled, pilot trial of methylphenidate and cognitive-behavioral group therapy for cocaine dependence in heroin prescription. J Clin Psychopharmacol. 2013;33:104-8.

42. Hart CL, Haney M, Vosburg SK, Rubin E, Foltin RW. Smoked cocaine self-administration is decreased by modafinil. Neuropsychopharmacology. 2008;33:761-8.

43. Dackis CA, Kampman KM, Lynch KG, Pettinati HM, $\mathrm{O}^{\prime}$ Brien CP. A double-blind, placebo-controlled trial of modafinil for cocaine dependence.

Neuropsychopharmacology. 2005;30:205-11.

44. Verrico CD, Haile CN, Mahoney Iii JJ, Thompson-Lake DGY, Newton TF, De La Garza Ii R. Treatment with modafinil and escitalopram, alone and in combination, on cocaine-induced effects: a randomized, double blind, placebo-controlled human laboratory study. Drug Alcohol Depend. 2014;141:72-8.

45. Anderson AL, Reid MS, Li S-H, Holmes T, Shemanski L, Slee A, et al. Modafinil for the treatment of cocaine dependence. Drug Alcohol Depend. 2009;104:133-9.

46. Dackis CA, Kampman KM, Lynch KG, Plebani JG, Pettinati HM, Sparkman T, et al. A double-blind, placebo-controlled trial of modafinil for cocaine dependence. J Subst Abuse Treat. 2012;43:303-12.

47. Comer SD, Sullivan MA, Hulse GK. Sustained-release naltrexone: novel treatment for opioid dependence. Expert Opin Investig Drugs. 2007;16:1285-94.

48. Comer SD, Sullivan MA, Yu E, et al. Injectable, sustained-release naltrexone for the treatment of opioid dependence: a randomized, placebo-controlled trial. Arch Gen Psychiatry. 2006;63:210-8.

49. Negus SS. Choice between heroin and food in nondependent and heroin-dependent rhesus monkeys: effects of naloxone, buprenorphine, and methadone. J Pharmacol Exp Ther. 2006;317:711-23.

50. Grabowski J, Rhoades H, Silverman P, Schmitz JM, Stotts A, Creson D, et al. Risperidone for the treatment of cocaine dependence: randomized, double-blind trial. J Clin Psychopharmacol. 2000;20:305-10.

51. Levin FR, McDowell D, Evans SM, Brooks D, Spano C, Nunes EV. Pergolide mesylate for cocaine abuse: a controlled preliminary trial. Am J Addict. 1999;8:1207.

52. Loebl T, Angarita GA, Pachas GN, Huang KL, Lee SH, Nino J, et al. A randomized, double-blind, placebocontrolled trial of long-acting risperidone in cocainedependent men. J Clin Psychiatry. 2008;69:480-6.

53. Smelson DA, Williams J, Ziedonis D, Sussner BD, Losonczy MF, Engelhart C, et al. A double-blind placebo-controlled pilot study of risperidone for decreasing cue-elicited craving in recently withdrawn cocaine dependent patients. J Subst Abuse Treat. 2004;27:45-9.

54. Kampman KM, Pettinati H, Lynch KG, Sparkman T, $\mathrm{O}^{\prime}$ Brien CP. A pilot trial of olanzapine for the treatment of cocaine dependence. Drug Alcohol Depend. 2003;70:265-73.

55. Reid MS, Casadonte P, Baker S, Sanfilipo M, Braunstein D, Hitzemann R, et al. A placebo-controlled screening trial of olanzapine, valproate, and coenzyme Q10/Lcarnitine for the treatment of cocaine dependence. Addiction. 2005;100:43-57.

56. Hamilton JD, Nguyen QX, Gerber RM, Rubio NB. Olanzapine in cocaine dependence: a doubleblind, placebo-controlled trial. Am J Addict. 2009;18:48-52.

57. Kishi T, Matsuda Y, Iwata N, Correll CU. Antipsychotics for cocaine or psychostimulant dependence: systematic review and meta-analysis of randomized, placebocontrolled trials. J Clin Psychiatry. 2013;74:e1169-80. A nice review and meta-analysis of dopamine antagonists and other antipsychotic medication treatment effects on cocaine use in clinical trials.

58. Woolverton WL, Balster RL. Effects of antipsychotic compounds in rhesus monkeys given a choice between 
cocaine and food. Drug Alcohol Depend. 1981;8:6978.

59. Brutcher RE, Nader MA. Effects of quetiapine treatment on cocaine self-administration and behavioral indices of sleep in adult rhesus monkeys.

Psychopharmacology. 2015;232:411-20.

60. Bergman J, Roof RA, Furman CA, Conroy JL, Mello NK, Sibley DR, et al. Modification of cocaine selfadministration by buspirone (Buspar ${ }^{\circledR}$ ): potential involvement of D3 and D4 dopamine receptors. Int J Neuropsychopharmacol. 2013;16:445-58.

61. Winhusen TM, Kropp F, Lindblad R, Douaihy A, Haynes L, Hodgkins C, et al. Multisite, randomized, double-blind, placebo-controlled pilot clinical trial to evaluate the efficacy of buspirone as a relapseprevention treatment for cocaine dependence. J Clin Psychiatry. 2014;75:757-64.

62. John WS, Newman AH, Nader MA. Differential effects of the dopamine D3 receptor antagonist PG01037 on cocaine and methamphetamine self-administration in rhesus monkeys. Neuropharmacology. 2015;92:3443.

63. Haney M, Ward A, Foltin R, Fischman M. Effects of ecopipam, a selective dopamine D1 antagonist, on smoked cocaine self-administration by humans. Psychopharmacology. 2001;155:330-7.

64. Haney M, Rubin E, Foltin R. Aripiprazole maintenance increases smoked cocaine self-administration in humans. Psychopharmacology. 2011;216:379-87.

65. Lofwall MR, Nuzzo PA, Campbell C, Walsh SL. Aripiprazole effects on self-administration and pharmacodynamics of intravenous cocaine and cigarette smoking in humans. Exp Clin Psychopharmacol. 2014;22:238-47.

66. Meini M, Moncini M, Cecconi D, Cellesi V, Biasci L, Simoni G, et al. Safety, tolerability, and self-rated effects of aripiprazole and ropinirole treatment for cocaine dependence: a pilot study. Am J Addict. 2011;20:179-80.

67. Thomsen M, Fink-Jensen A, Woldbye D, Wörtwein G, Sager T, Holm R, et al. Effects of acute and chronic aripiprazole treatment on choice between cocaine selfadministration and food under a concurrent schedule of reinforcement in rats. Psychopharmacology. 2008;201:43-53.

68. Bergman J. Medications for stimulant abuse: agonist-based strategies and preclinical evaluation of the mixed-action $\mathrm{D}_{2}$ partial agonist aripiprazole (Abilify ${ }^{\circledR}$ ). Exp Clin Psychopharmacol. 2008;16:475-83.

69. Czoty PW, Nader MA. Effects of dopamine D2/D3 receptor ligands on food-cocaine choice in socially housed male cynomolgus monkeys. J Pharmacol Exp Ther. 2013;344:329-38.

70. John W, Banala A, Newman A, Nader M. Effects of buspirone and the dopamine D3 receptor compound PG619 on cocaine and methamphetamine self- administration in rhesus monkeys using a food-drug choice paradigm. Psychopharmacology 2014:1-11.

71. Butelman ER, Yuferov V, Kreek MJ. k-Opioid receptor/ dynorphin system: genetic and pharmacotherapeutic implications for addiction. Trends Neurosci. 2012;35:587-96.

72. Walsh SL, Geter-Douglas B, Strain EC, Bigelow GE. Enadoline and butorphanol: evaluation of $\kappa$-agonists on cocaine pharmacodynamics and cocaine selfadministration in humans. J Pharmacol Exp Ther. 2001;299:147-58.

73. Negus SS. Effects of the kappa opioid agonist U50,488 and the kappa opioid antagonist nor-binaltorphimine on choice between cocaine and food in rhesus monkeys. Psychopharmacology. 2004;176:204-13.

74. Hutsell BA, Cheng K, Rice KC, Negus SS, Banks ML. Effects of the kappa opioid receptor antagonist norbinaltorphimine (nor-BNI) on cocaine versus food choice and extended-access cocaine intake in rhesus monkeys. Addict Biol. 2015.

75. Foltin RW, Fischman MW. Effects of buprenorphine on the self-administration of cocaine by humans. Behav Pharmacol. 1994;5:79-89.

76. Foltin RW, Fischman MW. Effects of methadone or buprenorphine maintenance on the subjective and reinforcing effects of intravenous cocaine in humans. J Pharmacol Exp Ther. 1996;278:1153-64.

77. Negus SS, Mello NK. Effects of chronic methadone treatment on cocaine- and food-maintained responding under second-order, progressive-ratio and concurrent-choice schedules in rhesus monkeys. Drug Alcohol Depend. 2004;74:297-309.

78. Mooney LJ, Nielsen S, Saxon A, Hillhouse M, Thomas $\mathrm{C}$, Hasson A, et al. Cocaine use reduction with buprenorphine (CURB): rationale, design, and methodology. Contemp Clin Trials. 2013;34:196-204.

79. Woolverton WL, Balster RL. The effects of lithium on choice between cocaine and food in the rhesus monkey. Commun Psychopharmacol. 1979;3:309-18.

80. Gawin FH, Kleber HD, Byck R, et al. Desipramine facilitation of initial cocaine abstinence. Arch Gen Psychiatry. 1989;46:117-21.

81.• Augier E, Vouillac C, Ahmed SH. Diazepam promotes choice of abstinence in cocaine self-administering rats. Addict Biol. 2012;17:378-91.

First demonstration of treatment efficacy on cocaine choice with a non-monoaminergic releasing compound in rodents.

82.• Thomsen M, Fulton B, Caine SB. Acute and chronic effects of the M1/M4-preferring muscarinic agonist xanomeline on cocaine vs. food choice in rats. Psychopharmacology. 2014;231:469-79.

Recent study demonstrating treatment efficacy to decrease cocaine choice with another potential non-monoaminergic releasing compound.

83. Carroll ME, Lac ST, Nygaard SL. A concurrently available nondrug reinforcer prevents the acquisition or 
decreases the maintenance of cocaine-reinforced behavior. Psychopharmacology. 1989;97:23-9.

84. Nader M, Woolverton W. Effects of increasing the magnitude of an alternative reinforcer on drug choice in a discrete-trials choice procedure.

Psychopharmacology. 1991;105:169-74.

85. Hart CL, Haney M, Foltin RW, Fischman MW. Alternative reinforcers differentially modify cocaine self-administration by humans. Behav Pharmacol. 2000;11:87-91.

86. Stoops WW, Lile JA, Glaser PE, Hays LR, Rush CR. Alternative reinforcer response cost impacts cocaine choice in humans. Prog Neuropsychopharmacol Biol Psychiatry. 2012;36:189-93.

First human laboratory study to demonstrate cocaine choice in humans is sensitive to 'cost' manipulations.

87. Nader MA, Woolverton WL. Effects of increasing response requirement on choice between cocaine and food in rhesus monkeys. Psychopharmacology. 1992;108:295-300.

88. Greenwald MK, Steinmiller CL. Cocaine behavioral economics: from the naturalistic environment to the controlled laboratory setting. Drug Alcohol Depend. 2014;141:27-33.

Empirically demonstrated that cocaine use in a naturalistic environment is sensitive to economic variables.

89. Higgins ST, Budney AJ, Bickel WK, Foerg FE, Donham $\mathrm{R}$, Badger GJ. Incentives improve outcome in outpatient behavioral treatment of cocaine dependence. Arch Gen Psychiatry. 1994;51:568-76.

90. SAMHSA. Results from the 2013 National Survey on Drug Use and Health: summary of national findings, S.A.a.M.H.S. Administration, Editor. 2014: Rockville, MD.

91. Federal Bureau of Investigation. Crime in the United States. 2014. http://www.fbi.gov/about-us/cjis/ucr/ crime-in-the-u.s/2013/crime-in-the-u.s.-2013/tables/ table29/table_29_estimated_number_of_arrests_ united_states_2013.xls.
92. Negus SS. Effects of punishment on choice between cocaine and food in rhesus monkeys.

Psychopharmacology. 2005;181:244-52.

93. Woolverton WL, Freeman KB, Myerson J, Green L. Suppression of cocaine self-administration in monkeys: effects of delayed punishment.

Psychopharmacology (Berl). 2012;220:509-17.

94. Kerstetter KA, Ballis MA, Duffin-Lutgen S, Carr AE, Behrens AM, Kippin TE. Sex differences in selecting between food and cocaine reinforcement are mediated by estrogen. Neuropsychopharmacology.

2012;37:2605-14.

First preclinical study to demonstrate potential gender differences in cocaine choice.

95. Perry AN, Westenbroek C, Becker JB. The development of a preference for cocaine over food identifies individual rats with addiction-like behaviors. PLOS ONE. 2013;8:e79465.

96. Evans SM, Foltin RW. Does the response to cocaine differ as a function of sex or hormonal status in human and non-human primates? Horm Behav. 2010;58:1321.

97. Banks ML, Blough BE. Effects of environmental manipulations and bupropion and risperidone treatments on choice between methamphetamine and food in rhesus monkeys.

Neuropsychopharmacology 2015. doi:10.1038/ npp.2015.63.

98. Stoops WW, Pike E, Hays LR, Glaser PE, Rush CR. Naltrexone and bupropion, alone or combined, do not alter the reinforcing effects of intranasal methamphetamine. Pharmacol Biochem Behav. 2015;129:45-50.

99. Shoptaw S, Heinzerling KG, Rotheram-Fuller E, Steward T, Wang J, Swanson A-N, et al. Randomized, placebo-controlled trial of bupropion for the treatment of methamphetamine dependence. Drug Alcohol Depend. 2008;96:222-32. 